\title{
Evaluating Agile Information-Based Framework for Flood Management Utilizing Metadata Concept to Support Flood Operation Activities
}

Preliminary communication

\author{
Mohamad Firdaus bin Mat Saad \\ School of Information Technology \\ SEGi College Penang \\ Penang, Malaysia \\ firdaus.ms@outlook.com
}

\author{
Aliza binti Abdul Latif \\ Department of Information System, School of Computing and Informatic \\ Universiti Tenaga Nasional, \\ Selangor, Malaysia \\ aliza@uniten.edu,my
}

\section{Marini binti Othman \\ Academic Consultant \\ Selangor, Malaysia}

\begin{abstract}
Operational policies are established to handle natural hazards including floods to minimize the effect with differing degrees of effectiveness and increasing relaxation. Sometimes policies are time-consuming of rigid protocols that are inadequate in a dynamic and somewhat chaotic environment synonymous with the complexity of flood disaster. Hence, this research aimed at recommending the incorporation of agile concepts in flood control, which would offer stability and adaptability in the control of the complex flood situation. Extensive reviews on flood management and existing frameworks for disaster management were conducted to understand the problems and the potential solution to construct an agile framework. A grounded analysis was conducted to obtain insight into how the agility of standard operating procedures could be enhanced. The agile components have been defined by contrasting characteristics from other effective disciplines, including software development and health care, that share common complexity in management environments. Consequently, an Agile Information-Based for Flood Management Framework is proposed in previous publication. The validation component for agile key-values presented in the earlier article is, however, absent. This study therefore presents the validation component from earlier publication on the Agile Information Based Framework. A theoretical evaluation of the proposed key-values for the agile framework has been conducted using the metadata concept. The evaluation identified the similarity feature in the same area where the proposed framework was agreed to be implemented in tandem with electricity company emergency response plan to improve flood operations. The proposed key-values in the agile framework are required to be adopted and further strengthened by other significant variables.
\end{abstract}

Keywords: Agile concept, Flood management, Flood operation, Metadata Model, Framework

\section{INTRODUCTION}

Managing floods is a complex process since every disaster including flood is unique in nature. Effective communication between emergency relief organizations, flood victims control, media pressure, time constraints, operational demand, technical and facilities limitations are the key factors that contributed to the complexity of the management process [1]-[4]. In such a situation, effective management methods need to be considered to achieve disaster management (DM) goals and objectives to increase flexibility, time to respond, and satisfaction of stakeholders (authorities, non-governmental organization (NGO), victims). In the area of systems development known as an agile management approach in a complex environment has indeed been adopted [5]-[8]. This included constantly evolving customer demands, time pressures, and customer satisfaction, which need to be addressed from time to time while promoting corporate and operational priorities. Taking into account the similarities of the complex characteristics in both environments, the agile concept is seen as a new approach in 
flood management. In fact, there are studies conducted by scholars to adapt the agile concept in disaster management [9]-[12]. Therefore, the AgiLe inFormationbAsed (ALFA) Framework for Flood Management has been introduced in previous publications where it details the development process of the proposed frameworks [18]. The concept of agility is presented in that paper, promising the flexible approach in managing the complexities during chaotic situations. However, there is a missing validation aspect of the framework. Hence, this paper purposely to present the validation process of the AFLA Framework for flood management to ensure the correctness, completeness, and relevance of the proposed key-values inside the framework to be generalized to the actual implementation.

Validation has been carried out to ensure all key-value introduced in the ALFA framework satisfy the requirements of the analysis and are therefore applicable to the real-world application. The main purpose of validation is to guarantee each key-value discussed by the researcher meets each domain of the study conducted. It is to demonstrate that perhaps the agile model can be applied to any management system if well designed. While the complex environment can adopt agile methods in the implementation process, the traditional, systematic, and knowledge-based management should be passionate about doing so. This research followed theoretical evaluation approaches that explain the definition of metadata to improve the dimension of the results for the proposed key-values in the ALFA framework. This is because the assessment made is dependent on the outcomes of the analysis carried out and then reviewed with the current facts. This theory directs the evaluator by defining the key elements of the framework and describes how these elements are structured to be connected [13]. According to S. Cojocaru, this theory is beneficial as it directs the evaluator by defining the key elements of the framework and describing how these elements are structured to be connected [13]. Other researchers claimed that the objective of a theory-based evaluation is to evaluate a model that is hypothesized to describe the program and the mechanisms used to produce the expected outcomes [14].

The key-values incorporated into this ALFA framework are confirmed by the proof from previous research, documentation, and even actual application of the SOP utilizing this theoretical assessment process. In this analysis, the evidence-based approach used is the official documentation involving the implementation of the main framework used at the international level, namely the Hyogo and Sendai frameworks [28] and the framework developed by local researchers (referring to Governance of Flood Disaster Framework (GFD) [36]) by following the causal type of the theoretical-driven evaluation to define and underlies the causal relationship between those frameworks. Therefore, to verify the suggested key-values in the ALFA framework, these key values have been tested with existing Standard Operating Procedure (SOP) or frameworks (referred to Hyogo and Sendai) and another similar framework (referred to GFD) developed in the field of research (focused on the sense of Malaysia). Taking into consideration the relationship between key values implemented through the ALFA framework by the metadata approach, it is expected that there would be a connection between the key values and the accessible facts.

This paper is organized as follows: in the second section, an overview of the works related to agile management will be elaborated. The third section will discuss the methodology used in validating the ALFA framework and followed with the definition of ALFA framework. The next section will provide the result of the validation performed on the framework. Concluding, we discuss the framework adoption with a sample disaster in an electricity company as well as future research of the framework.

\section{METHODOLOGY}

In this study, theoretical validation has been adopted by considering metadata elements presented in the ALFA framework. Metadata, according to E. Brodie is structured content that identifies, defines, finds, or otherwise facilitates the collection, usage, or management of an information resource [15]. Metadata is often referred to as data about data or information about information. The use of the word metadata varies according to the discipline of study [15]. Some of them use it to refer to understandable machine information, while others only use it to identify electronic services in documents. The metadata helps to provide appropriate and accurate information to get a real picture of resource quality [16]. In this case, a descriptive metadata approach has been adopted by the researcher to define resources. This method was used to identify elements such as title, abstract, keyword, or any other item that would explain how the resources are used. In resource collection, metadata performs the same purposes as successful cataloging does by (1) allowing resources to be found by relevant criteria, (2) identifying resources, (3) bringing similar resources together, (4) distinguishing dissimilar resources, and (5) giving location information [15]. At any level of aggregation, metadata may describe resources. A selection, a specific commodity, or a part of a larger resource can be represented. Hence, the usage of metadata for theoretical-based validation will account for data and information accuracy by providing the highest degree of outcome based on the theoretical methods adopted.

The theory of highly intuitive metaphor from the court of law was introduced using the outline of a witness' oath to ensure the consistency of information offered. By considering the statement takes in the court when witness swears to "... tell the truth (the correctness), the whole truth (the completeness), and nothing but the truth (the relevance)" [16]. All three elements from the theory; correctness, completeness and relevance were applied to validate the quality of the metadata provided in the ALFA framework. The quality of the metadata 
should emerge when the consistent data are associated with the domain (correctness), the data is provided with adequate information regarding data contents (completeness), and the ability to apply the data to the actual implementation (relevance).

Thus, to ensure uniformity of data introduced within the same context, which is disaster management specifically to the flood control, the identification of consistent data within the existing framework, firstly was applied, to the Hyogo and Sendai, the GFD, and the ALFA frameworks, for validation purposes. Secondly, to ensure the completeness of data, the integration and consideration of metadata information from the Hyogo and Sendai, and the GFD framework would be clarified in depth. Next, to demonstrate the relevance of the described data, the data should be clarified and implemented based on current practices concerning flood control. Thus, in the next sections, the presenter has presented the discussion and finding regards to the validation of the ALFA framework based on the theoretical evaluation using metadata methods.

\section{DEFINING ALFA FRAMEWORK}

The ALFA framework is a work-based framework on agile elements adapted from system development to disaster management. Due to the complex management features in system development, which has shifted from traditional management to agile management to allow the achievement of objectives promptly. While developing effective management, the agile approach is seen as a new benchmark for other areas of complex management including flood [17]. Many studies have been carried out on the acceptability of the agile concept in disaster management [9]-[12] by identifying the information of the agile concept adopted in disaster management. This research was additionally adopted observation, interviews, and formal training methodologies, to collect information relevant to agile management.

Literature reviews were conducted on system development, and health care to identify agile elements adapted in implementation in these two domains. Interviews with electricity company (EC) General Manager and the District and Land Office Director were performed to understand flood management practices and to define the agile concepts implemented in current flood management. Besides, observations have been made in many aspects of flood control, including emergency centers, evacuation centers, early-warning systems, water level monitoring systems, moorings, and flood management portals. Formal training has also been included in data collection to understand the overall flood disaster management practiced in Malaysia, particularly on the EC and District and Land Office operations as were presented in previous publication [18].

Based on the previous works, published in [18], seven agile elements have been identified from the study conducted. Among them are 1) Quick response, 2) Transfor- mational leadership, 3) Small project management, 4) Technology and innovation, 5) Coordination and communication, 6) Community Engagement, and 7) Practice and training in various disaster management (DM) aspect especially flood management as shown in Figure 1 [18]. All seven elements were analyzed using thematic coding methods based on the similarity of data obtained during the data collection [18]. The thematic analysis is the qualitative approach focused on the pattern under which the gathered information is evaluated in conjunction with the theme. The thematic analysis allows for a more precise theme in the way the different activities give significant advantages [19]. Therefore, the ALFA framework has been developed to coordinate flood management based on the agile elements found during data collection.

The analysis has then been explained by two main recommendations on successful flood management as proposed in the ALFA framework [18].

1. Certain elements have to take into account complex circumstances. It recognizes that the situation and the disaster context are unique, can vary and change with time. Adaptive approaches are therefore expected during implementation. In the proposed framework, under the 'agile process,' these elements are defined.

2. The strict SOP must be preserved (where flexibility is not permitted) to ensure the effective and organized complication of certain activities, for instance, were shutting down a substation operation. A sleek and transparent SOP is needed in every disaster organization. A structured SOP for this specific type of disaster management is also required to regulate the uniformity of the system applied.

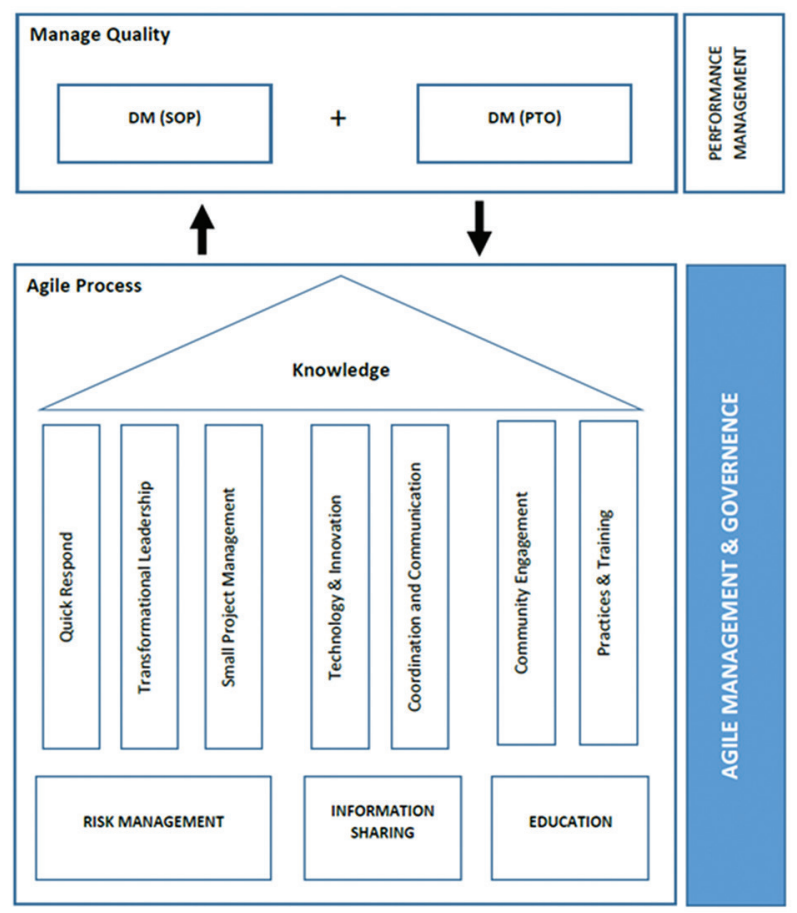

Fig. 1. Agile Information-Based Framework for flood management (The figure was reprinted from [18]) 
As a result, several aspects appear to be unproductive to an agile approach, for example, to define a Standard Operating Procedure (SOP) as a guideline in every management and administration practice. This rule is very specific to a limited part of the project. So, during implementation, these documentations could not adopt agility. However, there is a demand for post-evaluation or lessons learned from flood for future access and improvement to be documented and to use SOP for the smaller scope of activities for easy navigation. On the other aspect, agile key-values are introduced in the framework to manage flood, and the validation of the key-values would strengthen the finding. Hence the following section will present the validation phases of introduced agile key-values.

\section{RESULT AND DISCUSSION}

In this section, the researchers will present the validation process carried out on key-values established in the ALFA framework through the integration of the concept of metadata. Consistency of data in the actual implementation of the framework and management processes relates to disaster management are determined by the key-values. It is verified by the establishment of the relationship between the ALFA framework with the Hyogo \& Sendai as well as the GFD framework. On top of that, the detailed information about the data has been explained by integrating the Hyogo, Sendai, and GFD framework to justify the data in ensuring the completeness of the introduced key-values. The importance of the agile key values to be widespread in real implementation has been explained to strengthen metadata quality identified using T.Margaritopoulos theory [16]. The merger of correctness, completeness, and relevance of the key-values is structured to ensure the consistency of the provided metadata is relevant within the research domain and has been presented in Agile information-based framework for flood management [18]. Table 1 below provides important details on how the Hyogo, Sendai, and GFD frameworks have a connection to the ALFA key-values. In this section, the following are significant.

Table 1. Mapping of Hyogo, Sendai, and GFD framework to the key-values proposed in the ALFA framework

\begin{tabular}{|c|c|c|c|}
\hline $\begin{array}{l}\text { Key-Values } \\
\text { introduced in } \\
\text { ALFA Framework }\end{array}$ & Hyogo and Sendai Framework & GFD Framework & Relational to ALFA Framework \\
\hline SOP, Policy & $\begin{array}{l}\text { Both frameworks have adopted an } \\
\text { emergency response plan. }\end{array}$ & $\begin{array}{l}\text { GFD has emphasized designing and } \\
\text { enforcing environmental management } \\
\text { plans, initiatives, laws, and regulations for } \\
\text { FD operations. }\end{array}$ & $\begin{array}{l}\text { ALFA framework has introduced the use } \\
\text { of SOP to be integrated with the ALFA } \\
\text { framework. }\end{array}$ \\
\hline Knowledge & $\begin{array}{l}\text { Hyogo stressed the use of knowledge } \\
\text { to construct a culture of protection and } \\
\text { stability at all levels. }\end{array}$ & $\begin{array}{c}\text { To enhance performance and } \\
\text { competitiveness by maximizing capital, } \\
\text { GFD applied resources management to } \\
\text { people, competencies, and skills (refer } \\
\text { to knowledge) in the managing of flood } \\
\text { disasters. }\end{array}$ & $\begin{array}{l}\text { The ALFA framework discusses the value } \\
\text { of a strong understanding (knowledge) } \\
\text { of emergency reduction. }\end{array}$ \\
\hline Quick Response & $\begin{array}{c}\text { Hyogo has highlighted DRR strategies } \\
\text { integrated into priority } 4 \text { to reduce the } \\
\text { underlying risk factor with adaptation to } \\
\text { climate change. }\end{array}$ & None & $\begin{array}{l}\text { The ALFA framework underlines the } \\
\text { quick response, as it leads to disaster } \\
\text { management's effectiveness. }\end{array}$ \\
\hline $\begin{array}{l}\text { Transformational } \\
\text { Leadership }\end{array}$ & None & $\begin{array}{l}\text { GFD emphasized the key point in which } \\
\text { the public must know how to play an } \\
\text { active role in the flood disaster. }\end{array}$ & $\begin{array}{c}\text { The ALFA framework explains the } \\
\text { value of transformational leadership } \\
\text { to encourage more efficient disaster } \\
\text { management. }\end{array}$ \\
\hline $\begin{array}{l}\text { Small Project } \\
\text { Management }\end{array}$ & $\begin{array}{l}\text { Hyogo highlighted raising the } \\
\text { fundamental risk factor in balanced } \\
\text { biodiversity and environmental } \\
\text { management. }\end{array}$ & None & $\begin{array}{l}\text { Throughout its more achievable } \\
\text { form, small project management is } \\
\text { highlighted in the ALFA Framework. }\end{array}$ \\
\hline $\begin{array}{l}\text { Technology and } \\
\text { Innovation }\end{array}$ & $\begin{array}{l}\text { Hyogo emphasized the advancement } \\
\text { of technologies and the usage of } \\
\text { technology (early warning, data sharing) } \\
\text { as resources for crisis relief. }\end{array}$ & $\begin{array}{l}\text { To promote interactions and knowledge } \\
\text { exchange on flood control, GFD } \\
\text { implemented nationwide flood system } \\
\text { components to act as end-to-end IT } \\
\text { infrastructures. }\end{array}$ & $\begin{array}{l}\text { The ALFA framework involves } \\
\text { technology and innovation because } \\
\text { it has significance for improving } \\
\text { emergency recovery plans. }\end{array}$ \\
\hline $\begin{array}{l}\text { Coordination and } \\
\text { Communication }\end{array}$ & $\begin{array}{l}\text { Hyogo and Sendai underlined the } \\
\text { coordination, information sharing, and } \\
\text { use of standard DRR terminology for } \\
\text { effective response. }\end{array}$ & $\begin{array}{l}\text { For efficient resource allocation in the } \\
\text { FM Process, GFD has adopted the idea of } \\
\text { collaboration and exchanging capital. }\end{array}$ & $\begin{array}{l}\text { The ALFA framework emphasizes } \\
\text { coordination and communication } \\
\text { because of its beneficial qualities during } \\
\text { the emergency recovery phase. }\end{array}$ \\
\hline $\begin{array}{l}\text { Community } \\
\text { Engagement }\end{array}$ & $\begin{array}{l}\text { Hyogo stressed community involvement } \\
\text { as one of the important areas for } \\
\text { developing a better DRR plan. }\end{array}$ & None & $\begin{array}{l}\text { Community engagement in emergency } \\
\text { recovery also leads to effective disaster } \\
\text { management. The ALFA framework } \\
\text { thus further outlines community } \\
\text { engagement as a primary element. }\end{array}$ \\
\hline $\begin{array}{l}\text { Practices and } \\
\text { Training }\end{array}$ & $\begin{array}{l}\text { Hyogo stressed the importance of } \\
\text { education, training, public awareness, } \\
\text { review, and exercise plans in the area of } \\
\text { preparedness and emergencies plan. }\end{array}$ & $\begin{array}{l}\text { In cooperation with public and private } \\
\text { organizations worldwide, the GFD } \\
\text { introduced the idea of Education, } \\
\text { Research, and Partnership (ERP). }\end{array}$ & $\begin{array}{l}\text { The ALFA framework adapts practices } \\
\text { and training owing to its capacity for } \\
\text { effective disaster management. }\end{array}$ \\
\hline
\end{tabular}


Table 1 presented the interconnection of the elements between Hyogo, Sendai, GFD, and ALFA frameworks. The consistency of the elements in the established (refer to Hyogo, Sendai) frameworks and similar (refer to GFD) framework, have strengthened the keyvalues proposed in the ALFA framework. The explanation below should clarify the completeness and relevance of key-values for actual flood operations.

The usage of SOP, and Policy in emergency recovery has been enforced formally by the primary disaster management agency, the National Security Council (NSC), which has now been carried up by the National Disaster Management Agency (NADMA) [20]. Directive No.20 is the primary emergency response guideline used in Malaysia [21], [22]. Every agency or organization has developed an internal SOP, in the meantime. EC has outlined the three SOPs for an emergency, including Corporate Emergency Respond Plan (CERP), and System and Non-system Emergency Respond Plan [23], [24]. For SOPs such as these, emergency recovery perhaps to be more easily managed. Nevertheless, it is argued whether the SOPs relative to the form of disaster should be more comprehensive, and the handling mechanism should also be narrower.

As important as SOP, and Policy implementation, it is critical to have a general understanding of an uncommon situation. Yet it is more important to provide a detailed understanding of the severity of issues. It is because knowledge has a significant part to play in deciding intervention. As a society, it is important to stress fundamental information regarding flood control, as it affects the living, properties, and everyday life. It helps the public to respond to issues that occur without waiting for orders or actions from the authorities, with the knowledge of flood control, because it impacts the life of the population. The enhancement of knowledge management and integration has been explored by many researchers in Malaysia in regards to disaster management [25]-[27]. Therefore, knowledge should be seen as an essential factor of flood control such that actions can be done following the issues occurring, the condition, the current circumstance, and the complexity of the issue that requires agile intervention.

Not to neglect, the importance of the quick response element in disaster management is viewed as a revolutionary approach that might have a successful influence on flood control. The Hyogo framework has used the concept since it was introduced in the year 2005 [27], [28]. However, the implementation remains disappeared. Adjusting the idea of a quick response when an incident occurs is viewed as an early step to mitigate the threats from expanding to certain regions. For some other cases, this quick response principle can be extended. Nonetheless, persons who can react effectively to a problem, have some main reasons, which is to save a life, to adjust rapidly to efficiently performed. A detailed understanding of the problem, experience in the decision-making phase, awareness about the data and information processing facilities, and other considerations that may influence the person to make a swift decision about the problem are some of the factors to be considered.

Another important aspect is the transformation leadership. This concept is an interactive viewpoint that encourages everyone to be a leader in flood control. This term is referred to as transformation leadership as it will affect flood control by offering experts who are not generally recognized (non-lead management staff) to handle specific flood operation activities. This approach enables everyone to manage the situations from their experience or knowledge in flood management. It gives both the local population and the middle or lower management the ability to serve as the leader in flood operations. This is not the concept of only top managers will make the decisions. The IC, often the general manager, is appointed as a director to take full responsibility for crisis management immediately in actual deployment cases of the EC. If the general manager is unavailable, the responsibilities go to the second higher-position workforce, followed by seniority.

Whereas the idea of small project management is to break the project into a limited size such that the operation can be efficiently carried out within a reasonable amount of time and resources. The complicated task can be easily dealt with provided it has been narrowed down to a reduced size of the operation [6]. EC defined three types of SOPs, including the Corporate Emergency Response Plan (CERP) and the System and Non-System Emergency Response Plan. The unique SOP designed by EC is one of the aspects to reduce operational activities related to flood management.

In any case, technology is a medium that enables certain items to be linked by technology-based services, such as discovering information by internet facilities, weather forecasting via the forecasting system, managing the modern aviation environment through global positioning systems, and many more. Technology is now used as a significant element for disaster management, including floods, as essential to management function. This will implicitly help the flood control mechanism and reduces the likelihood due to flood through the presence of technology. This can be demonstrated in recent findings by scholars on the usage of technologies to control disaster operations [29]-[31]. EC has used telephone and mobile phones for internal or external communications and the dissemination of information. The information should be conveyed by using the reachable devices as this is simpler in contrast to the usage of fax, message, and info blast. The same details would, therefore, be faxed to agencies as evidence that the knowledge is exchanged by EC and agencies. The purpose of the message and info blast is to remind the community (headman) of the current situation and the actions to be complied with by the potential victims (applied only at a certain station). Nevertheless, there are two independent views on the 
involvement of social media to be used as a platform for channelling information to potential victims or agencies. However, the utilization of technology and innovation in channelling information, communicate with other stakeholders, and coordinate information and mission is the concept of agility where it may provide benefits to the flood control team.

Apart from the points discussed above, coordination and communication are the other important aspect of flood management as proposed in the ALFA framework. Coordination can be described as a collaboration between agencies or organizations in managing the activities related to the event, with the main goal of enhancing the quality of the operations [32]. To safeguard the effectiveness of flood control, cooperation between stakeholders is very critical. It involves cooperation between authorities, the public, and the victims of floods. Coordination of crisis management between the public and private sectors (locally, nationally, and internationally) is becoming increasingly relevant and effective. There are two kinds of coordination often mentioned: vertical and horizontal coordination. Vertical coordination is defined as the correlation between two or more organizations that share their duties, resources, and information to support similar end customers while horizontal coordination is based on internal communication, operational or group alliances, or mutual collaboration with competitors and non-competitors [32], [33]. On the other hand, the communication aspect during and after a disaster is a vital aspect of response and recovery, as it unites flood victims into touch with first responders, support systems, and other family members. For the survival of society, therefore, an accessible and reliable means of communication is very important. The consequences of the tragedy are not only for victims but also for families, friends, emergency responders, and care providers. The complexity of this significant incident has raised the concern of the need for more comprehensive and efficient communication and management approaches [34].

As important as the elements discussed above, a society is a group of people living or possessing the same characteristics in the same location. A society grows in depth when a collective of people who have specific characteristics relevant to social interaction, exchange common experiences and take cooperative action in an environment or geographical position [35]. To improve their capacity and capabilities to cope with disasters by themselves, society should be active and enable them to engage actively in any phase of a crisis management process. Also, community engagement in decision-making and active interest in developing an SOP is one means of strengthening emergency response strategies. This is because affected groups are the best markers of their vulnerability and can agree about their wellbeing adequately [35]. In the EC practices, local heroes were first formed to distribute information, expose disaster control activities and search and rescue, and all relevant emergency procedures to be taken out and carry out throughout the preparation phase in the context of an actual tragedy. The local heroes, whether the leader of the community or the interested representative (community participation) are listed. EC shall relay incident details through SMS or WhatsApp. Clear notice of potential disasters was issued to the local heroes to be vigilant or to act accordingly.

Lastly, practices and training are structured to ensure that everybody is completely educated and ready to respond as directions are given in any circumstance. Throughout the development of coordination, communication, and awareness between all rescue agencies, flood simulation is essentially needed. All rescue agencies have the same mission to save people from crises. This simulation is, therefore, necessary to let all organizations understand the operation of flood management, including local citizens' support. Even each organization has a different SOP, the key priority is to ensure that the emergency operations performed in the actual situation are carried out properly. This was intended that the flood program has been implemented and educated three times a year at EC-level, where EC is demanded to implement the appropriate emergency response plan protocol due to the critical operation during the flood involves the continuous supply of the electricity to the non-inundated area while off system to affected areas. However, the use of genset or mobile genset may serve as an alternative for the continuous operation of electricity in the inundated areas.

All the key principles presented in the agile sense have been inferred to be accepted frameworks. This is focused on metadata found from main frameworks used locally and internationally for disaster management (referred to in the Hyogo and Sendai) and also in the sense of flood governance (referred to in the GFD) developed by researchers in Malaysia. The plurality of core principles shared in an ALFA framework by scholars contains parallels from all areas of the frameworks. Nonetheless, keyvalues addressed in the suggested ALFA framework, which are not underlined by GFD are explored within the Hyogo and Sendai context and vice-versa.

\section{CONCLUSION AND RECOMMENDATION}

In a conclusion, the ALFA framework is not the same as the current framework that companies, governments, or academics in various fields have utilized or published. It is the emerging agile framework, a structure that can be tailored to any framework or SOPs for disaster management (refer to performance management in the AFLA framework) including the emergency response plan under EC and GDF framework. ALFA framework promises the operational aspects of flood management that can be adaptive in the application phase depending on the actual situation. As mentioned above where all the agile concepts introduced in the ALFA framework are tailored to the real flood management scenario. This is intended to offer an indi- 
cation of incorporating the suggested ALFA framework into the actual implementation. The proposed framework also provides an agile management philosophy in implementation or operation activities either before, during, or after the flood, depending on the suitability to be adopted with the current SOP.

However, a thorough analysis of the management cycle of an agile dimension in other complex environments such as hospital management, airplane accident, building collapse, and some other relevant fields will strengthen the finding of agile key-values as proposed in the ALFA framework to be implemented as a directed process. On the other hand, the implementation of the ALFA framework over different types of geographical and topology will provide better information and improvement to the proposed framework. Hence, the framework demands the implementation from a variety of structures to improve the content and implementation.

\section{REFERENCES:}

[1] B. B. R. Turner, „Balancing Agility and Discipline: A Guide for the Perplexed“", $7^{\text {th }}$ ed. Uniten States: Pearson Education, Inc, 2009.

[2] M. . Dorasamy, M. . Raman, and M. . Kaliannan, "Evaluating CEMAS in simulated environment to support disaster management challenges", Proceedings of the $11^{\text {th }}$ International Conference on Information Systems in Crisis Response Management, 2014, pp. 444-453.

[3] C. Pathirage, K. Seneviratne, D. Amaratunga, R. Haigh, "KNOWLEDGE FACTORS AND ASSOCIATED CHALLENGES FOR SUCCESSFUL DISASTER KNOWLEDGE SHARING Prepared for the Global Assessment Report on Disaster Risk Reduction 2015", No. January 2014, 2014.

[4] M. Yu, C. Yang, Y. Li, "Big data in natural disaster management: A review", Geosciences, Vol. 8, No. $5,2018$.

[5] M. Hneif, S. Hock ow, "REVIEW OF AGILE METHODOLOGIES IN SOFTWARE", International Journal of Research and Reviews in Applied Sciences, Vol. 1, No. 1, 2009, pp. 1-8.

[6] K. N. Rao, G. K. Naidu, P. Chakka, "A Study of the Agile Software Development Methods, Applicability and Implications in Industry", International Journal of Software Engineering and Its Applications, Vol. 5, No. 2, 2011, pp. 35-46.
[7] H. Hajjdiab, A. S. Taleb, "Adopting Agile Software Development: Issues and Challenges", International Journal of Managing Value and Supply Chains, Vol. 2, No. 3, 2011, pp. 1-10.

[8] K. Pathak, A. Saha, "Review of Agile Software Development Methodologies", Advances in Computer Science and Information Technology, Vol. 3, No. 2, 2013, pp. 270-276.

[9] A. I. Nawaz, I. A. Zualkernan, "The Role of Agile Practices in Disaster Management and Recovery: A Case Study", Proceedings of the Conference of the Center for Advanced Studies on Collaborative Research, November 2009, pp. 164-173.

[10] K. A. Abdelouhab, D. Idoughi, C. Kolski, "Agile \& user centric SOA based service design framework applied in disaster management", Proceedings of the 1st International Conference on Information and Communication Technologies for Disaster Management, Algiers, Algeria, 24-25 March 2014.

[11] L. L. Salvadó, M. Lauras, T. Comes, B. Van de Walle, "Towards More Relevant Research on Humanitarian Disaster Management Coordination", in Procedings of the ISCRAM, 2015.

[12] J. G. Brown, A. Chennamaneni, "Towards an Integrated Framework for Applying the Agile Project Methodology to Manage Task Uncertainty in Disaster Management", Proceedings of the Americas Conference on Information Systems, 2013, pp. 1-7.

[13] S. Cojocaru, "Clarifying the theory-based evaluation", Revista de Cercetare si Interventie Sociala, Vol. 26, 2009, pp. 76-86.

[14] G. Sharpe, N. Bay, "A Review of Program Theory and Theory-Based Evaluations 100 College Drive 1 . Purpose of the Paper 3 . When to develop a program theory 4. Components of a program theory", American International Journal of Contemporary Research, Vol. 1, No. 3, 2011, pp. 1998-2001.

[15] E. Brodie, "Understanding M.E.,' Nursing Times, Vol. 84, No. 31, 1988, pp. 48-49.

[16] T. Margaritopoulos, "A Conceptual Framework for Metadata Quality Assessment Merkourios Margaritopoulos", Proceedings of the International Conference on Dublin Core and Metadata Applications, 2008, pp. 104-113. 
[17] G. Becker, D. Huitema, J. C. J. H. Aerts, "Prescriptions for adaptive comanagement: The case of flood management in the german rhine basin", Ecology and Society, Vol. 20, No. 3, 2015.

[18] M. Firdaus, M. Saad, A. A. Latif, M. Othman, “Agile information-based framework for flood management", Proceedings of the Annual Conference on Computer Science and Engineering Technology, , Medan, Indonesia, 23 September 2020.

[19] M. Maguire, B. Delahunt, “Doing a Thematic Analysis : A Practical , Step-by-Step Guide for Learning and Teaching Scholars",Reflections, Journeys and Case Studies, Vol. 3, No. 3, 2017.

[20] N. O. Chong, K. H. Kamarudin, "Disaster risk management in Malaysia: Issues and challenges from the persepctive of agencies", Planning Malaysia, Vol. 16, No. 1, 2018, pp. 105-117.

[21] Major Mohd Sakri Hussin, “Disaster Management (NSC Directive No.20) A Malaysian Perspective by National Security Division Prime Minister Department", 2015.

[22] A. R. Badruddin, "Issues of Disaster Management Preparedness: A Case Study of Directive 20 of National Security Council Malaysia", International Journal of Business and Social Science, Vol. 3, No. 5, 2012, pp. 85-92.

[23] Tenaga Nasional Berhad, "STATEMENT ON RISK MANAGEMENT This Statement on Risk Management and Internal Control has been Malaysia 's Listing Requirements and Risk Management and Internal", 2013.

[24] N. H. Din, Datuk Ir. Baharin; Abd Kadir, Hjh Kamaliah; S., Parameswaran; Ibrahim, Ruslinda; MZ Halim, "After the Storm. Improved Safetr Measure in Hand, TNB Stads Ready for Future Floods", TenagaLink, 2015.

[25] M. N. Ahmad, M. Othman, N. H. Zakaria, M. Z. Mohd Rodzi, "Managing information and knowledge in Malaysia's flood management: Towards a new framework", Frontier in Artificial Intelligence Applications, Vol. 265, 2014, pp. 446-463.
[26] Y. Ali, A. Mohammad, N. Ahmad, N. Hidayati, "Knowledge Sharing Framework for Disaster Management", Journal of Information Systems Research and Innovation, Vol. 9, 2015, pp. 50-60.

[27] H. D. M. T. A. Wahab, “Malaysia - National progress report on the implementation of Hyogo Framework for Action (2009-2011)", Malaysia, 2011.

[28] UNISRD, "Hyogo Framework for Action 2005$2015:{ }^{* \prime \prime}, 2005$.

[29] E. Nations, ICT for Disaster Risk Reduction. 2010.

[30] J. Wilson, F. Wilson, J. Wilson, "The use of ICT in Disaster Risk Management: A Case Study of Nema Borno State", Journal of Remote Sensing GIS \& Technology, Vol. 5, No. 1, 2018, pp. 44-66.

[31] H. Yuliandoko, Subono, S. H. Pramono, P. Siwindarto, "Innovation technology for disaster management", International Journal of Recent Technology and Engineering, Vol. 8, No. 1, 2019, pp. 396-398.

[32] M. Bahadori, H. R. Khankeh, R. Zaboli, I. Malmir, "Coordination in Disaster: A Narrative Review", International Journal of Medical Reviews, Vol. 2, No. $2,2015$.

[33] R. Kaynak, A. T. Tuğer, "Coordination and Collaboration Functions of Disaster Coordination Centers for Humanitarian Logistics", Procedia - Social and Behavioral Sciences, Vol. 109, 2014, pp. 432-437.

[34] R. Moorthy, G. Benny, S. S. Gill, "Disaster communication in managing vulnerabilities", Malaysian Journal of Communication, Vol. 34, No. 2, 2018, pp. 51-66.

[35] H. A. Rahman, "Community Based Approach Towards Disaster Management in Malaysia", Asian Journal of Environment, History and Heritage, Vol. 2, No. 2, 2018, pp. 55-66.

[36] S. Maidin, M. Othman, "Governance of the Flood Disaster Framework in Malaysia: A Way Forward in Enabling Information Technology Knowledge Sharing", Journal of Advanced Research in Dynamical and Control Systems, Vol. 11, No. 1, 2019, pp. $1533-1541$. 